УДК 336.71

А. Р. Грошев

Сургутский государственный университет, г. Сургут, Российская Федерация

В. С. Павлов

Сургутский государственный университет, г. Сургут, Российская Федерация

\title{
ОЦЕНКА ЭФФЕКТИВНОСТИ ИСПОЛЬЗОВАНИЯ КАПИТАЛА БАНКА С УЧЕТОМ ПРИНИМАЕМЫХ РИСКОВ
}

\begin{abstract}
АНнотАЦИЯ. Замедление экономического роста, а также нестабильная экономическая ситуация в России оказывают существенное неблагоприятное воздействие не только на промышленный, но и на финансовый сектор страны. Кредитные организации сталкиваются с множеством трудностей в процессе управления рисками и распределения капитала. Большинство кредитных организаций в России применяют базовые подходы в пользу продвинутых методов оценки рисков и распределения капитала, что не позволяет в полной степени контролировать деятельность банка, учитывать специфику его работы и правильно оценивать возможные последствия от размещения активов. На основе анализа современных методов и международной практики в статье были даны рекомендации по применению методики, основанной на показателях, характеризующих рентабельность капитала, скорректированную на уровень риска.

кЛЮЧЕВЫЕ СЛОВА. Кредитные организации; риск-менеджмент; управление капиталом; оценка рисков; экономический капитал; рентабельность капитала.

ИНФОРМАЦИЯ О СТАТЬЕ. Дата поступления 20 апреля 2016 г.; дата принятия к печати 30 мая 2016 г.; дата онлайн-размещения 25 июля 2016 г.
\end{abstract}

A. R. Groshev

Surgut State University, Surgut, Russian Federation

V. S. Pavlov

Surgut State University, Surgut, Russian Federation

\section{ASSESSING EFFICIENCY OF USING BANK EQUITY IN TERMS OF ACCEPTED RISKS}

\begin{abstract}
Economic slowdown and unstable economic situation in Russia have significant negative influence not only on the industrial sector but also on the financial one. Credit institutions are facing many difficulties in the process of risk management and capital allocation. Most of the credit institutions in Russia use basic approaches in favor of advanced methods of risk assessment and capital allocation which does not allow to entirely control banking activities, to consider specificity of its performance and to assess the possible consequences of asset allocations correctly. On the basis of analysis of modern methods and international practice of risk assessment and capital allocation in terms of risk levels, the article gives recommendations on using the risk level-adjusted methodology based on indicators that characterize the return on equity.
\end{abstract}

KEYWORDS. Credit institutions; risk management; capital management; risk assessment; economic capital; return on equity.

ARTICLE INFO. Received April 20, 2016; accepted May 30, 2016; available online July $25,2016$.

(C) A. Р. Грошев, В. С. Павлов, 2016

\section{Baikal Research Journal}


На сегодняшний день на фоне экономического кризиса деятельность банков связана с повышенной концентрацией кредитного, рыночного, стратегического и прочих рисков. Падение курса рубля, рост ключевой ставки, массовое сокращение производства существенно усложняют кредитование как с точки зрения снижения темпов прироста ссудного портфеля, так и с позиции платежеспособности клиентов.

Несмотря на положительную динамику ссудной задолженности в 2014-2015 гг., увеличивается и объем создаваемых резервов и просроченной задолженности. На конец 2015 г. объем кредитов и прочих ссуд составил 57,5 трлн р., что на 23,5 трлн больше, чем на начало 2013 г. (рис. 1).

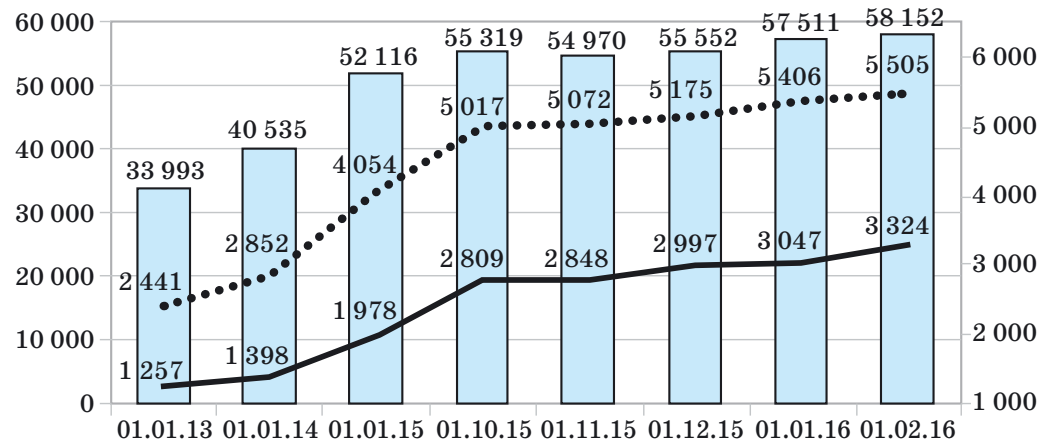

Кредиты и прочие ссуды — Просроченная задолженность

Рис. 1. Динамика ссудной срочной и просроченной задолженности, а также резервов на возможные потери в целом по банковскому сектору России в 2013-2016 гг., млрдр.

(Составлено по: URL: http://www.cbr.ru/analytics/?PrtId=bnksyst)

По данным приведенного графика (см. рис. 1) также видно, что объем просроченной задолженности увеличился до 3 трлн р., а объем созданных резервов на начало 2016 г. оказался 5,4 трлн р. Таким образом, доля просроченной задолженности в кредитном портфеле на начало 2016 г. составила 5,3 \%, а наибольший прирост пришелся на 2015 г. - 1,5 \% . Доля резервов на возможные потери в общем объеме пассивов на начало 2016 г. составила 6,5 \% (прирост за 2015 г. - 1,4 \%). Из этого следует, что почти за 3 года объем ссудной задолженности увеличился на 69,2 \% при росте просроченной задолженности на $142,4 \%$, а прирост пассивов банковского сектора составил $67,6 \%$ при росте резервов на $121,4 \%$. Однако стоит также отметить, что в 2015 г. темп роста объемов кредитования на конец декабря составил лишь 110,3 \% (2013 г. - 119,2 \% ; 2014 г. - 128,6 \% ).

Аналитики прогнозируют сокращение количества банков в России до 500 в ближайшие 2-3 года. Проблема в том, что эффективность банковской системы России по-прежнему на крайне низком уровне, а Банк России продолжает «расчистку» сектора от недобросовестных игроков [1]. Так, по данным Агентства по страхованию вкладов, за последние 2 года было зафиксировано 138 страховых случаев, т. е. отозвано 138 лицензий у банков участников системы страхования вкладов (рис. 2), а бюджет фонда сократился до 37,5 млрд р. Отметим, что по итогам 2015 г. в систему страхования вкладов входило 842 банка.

В текущих условиях неопределенности макроэкономической среды методы, позволяющие учитывать ее в управлении, чрезвычайно актуальны. Важным при этом является процесс управления риском, где риск - это не сама неопределенность, а функционирование экономических субъектов в условиях неопределенности. Существование фактора риска и неизбежные изменения его степени являются свое-

\section{Baikal Research Journal}


образной движущей силой перемещения в экономике материальных, финансовых и трудовых ресурсов и обеспечивают экономический прогресс общества в целом. Основные структурные характеристики риска: опасность, подверженность риску, уязвимость (чувствительность к риску) и степень взаимодействия рисков [2;3].

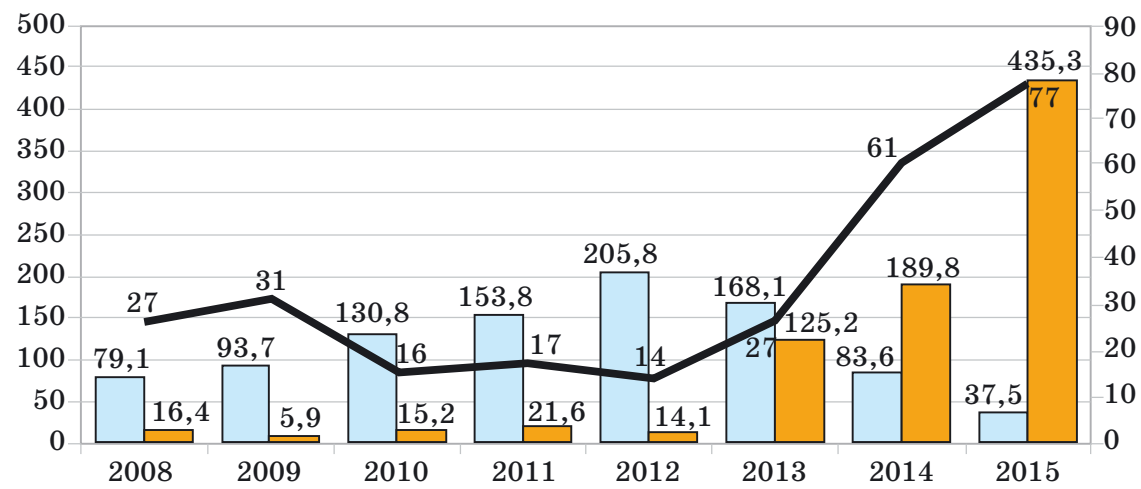

$\square$ Бюджет, млрд р. $\square$ Страховая ответственность, млрд р. $\quad$ Страховые случаи, шт.

Рис. 2. Диналика страховых случаев и объема фонда Агентства по страхованию вкладов в 2008-2015 г2. (Составлено по: URL : http://www.asv.org.ru/agency)

В процессе осуществления своей деятельности организация всегда принимает на себя различного рода риски. Практика показывает, что чем выше риск, тем больше возможность получения прибыли. Связь между доходностью операций и риском в упрощенном виде выражена линейной зависимостью. В реальной же практике линейная зависимость риска и доходности нарушается и приобретает очертания параболы, довольно часто возникают ситуации получения только убытков [4].

Рассмотрение взаимосвязи взаимного влияния капитала банка и кредитного, рыночного и операционного рисков, обусловленных его деятельностью, в определенной степени регламентируются требованиями Банка России, последовательно внедряющего в российскую банковскую практику рекомендации Базельского комитета по банковскому надзору [5, с. 134].

На сегодняшний день культура управления риском в кредитных организациях Российской Федерации не всегда позволяет поддерживать необходимую доходность, оптимальный уровень достаточности капитала и эффективно его распределять.

В российской практике существует два ключевых подхода к агрегированию рисков: базовый и продвинутый.

Базовый подход предполагает агрегацию кредитного, рыночного и операционного рисков, скорректированных на плановый уровень достаточности капитала. Данная методика описывается инструкцией Банка России «Об обязательных нормативах банков» от 3 декабря 2012 г. № 139-И (далее - инструкция 139-И) и положением «О расчете величины собственных средств (капитала), обязательных нормативов и размеров (лимитов) открытых валютных позиций банковских групп» от 3 декабря 2015 г. № 509-П. Учет прочих рисков в величине необходимого капитала банки определяют самостоятельно. Данный метод связан с использованием исключительно регуляторного (или регулятивного) капитала в рамках риск-менеджмента банка. На данный момент нормативно-правые акты не содержат какой-либо трактовки понятия регуляторного капитала, который, на наш взгляд, стоит понимать, как объем собственных средств банка, необходимый для покрытия возможных по-

\section{Baikal Research Journal}


терь от реализации рисков, размер которого определяется в соответствии с методикой, установленной регулятором.

Продвинутый подход, как правило, предполагает расчет экономического капитала по внутренним методикам банка в рамках общепринятых стандартов мировой практики.

Российские банки в основном применяют базовый подход - 9 из 11 опрошенных банков используют суммирование для агрегирования рисков ${ }^{1}$, а крупные международные банки - более продвинутые модели (IFRI/CRO Forum, 2007): свыше 60 \% опрошенных банков используют вариационно-ковариационный подход и лишь $20 \%$ простое суммирование [6].

Применение базового подхода в пользу продвинутого не позволяет банкам учитывать специфику их работы. Кроме того, применение продвинутого подхода позволяет более гибко и оперативно управлять рисками, повышать качество риск-менеджмента в целом и увеличивать отдачу на капитал.

Важным аспектом деятельности банка является применение внутренних процедур оценки достаточности капитала (ВПОДК). В российском законодательстве основные требования к ВПОДК регламентированы указанием Банка России «О требованиях к системе управления рисками и капиталом кредитной организации и банковской группы» от 15 апреля 2015 г. № 3624-У.

Задачи, решаемые в рамках системы управления рисками, следующие:

- выявление принятых и потенциальных рисков;

- выделение значимых рисков;

- оценка значимых рисков;

- агрегирование количественных оценок рисков;

- контроль за объемами значимых рисков.

В целях реализации ВПОДК в российской практике KPMG International, представитель компаний «Большой четверки» в сфере консалтинговых и аудиторских услуг, дает следующие рекомендации:

1. Не нужно создавать отдельный, обособленный процесс - ВПОДК представляет собой набор инструментов, который помогает повысить эффективность управления рисками и управлять риск/доходностью в банке.

2. Необходимо вовлечение регулятора на ранней стадии при реализации ВПОДК для обеспечения соответствия между их целями и планами банка.

3. Требуется определить риск-аппетит с использованием количественных и качественных критериев в соответствии с возможностями оценки (расчета) и стратегией банка.

4. Не нужно избавляться от действующих в банке подходов - нужно реально оценивать ситуацию и использовать все возможности, чтобы модернизировать существующие инструменты оценки риска, которые являются менее затратными.

5. Необходимо обеспечить согласованность между подходами ВПОДК и процедурами планирования и прогнозирования.

Одной из ключевых задач в рамках ВПОДК является идентификация полного перечня всех возможных рисков: присущих деятельности банка (рыночные, операционные, кредитные и прочие риски) и потенциальных (т. е. новых видов (дополнительных объемов) рисков, возникновение которых обусловлено реализацией мероприятий, предусмотренных стратегией развития банка).

Все идентифицированные риски необходимо классифицировать по уровню значимости. Идентификация риска - это предварительный этап его оценки, который заключается в описании следующих элементов риска:

${ }^{1}$ Ассоциация российских банков. URL : http://arb.ru/.

\section{Baikal Research Journal}


- источники риска (какие виды операций банка подвержены риску);

- события риска (выполнение каких условий считается реализацией риска);

- их причины (внешние/внутренние);

- возможные последствия (как правило, убыток, но не для всех видов риска) [7].

Методы идентификации при этом определяются самостоятельно каждым банком. К основным можно отнести анализ внешних источников и отчетности (нормативно-правовые акты Банка России, рекомендации международного, регионального и национального банковского регулирования, отраслевые стандарты, публичные информационные ресурсы, финансовая отчетность банка, заключения рейтинговых агентств, результаты проверок Банка России и службы внутреннего аудита), а также экспертиза с созданием рабочих групп (мозговой штурм, чек-листы, анализ сценариев).

После проведения идентификации рисков необходимо их классифицировать. По результатам данной классификации можно будет выбрать подход к оценке и управлению по каждому из видов рисков, в том числе определение потребности в капитале. Для классификации мы предлагаем разделять риски на следующие группы:

- значимые риски - риски, реализация которых существенно влияет на финансовую стабильность банка, его финансовый результат и на оценку достаточности капитала;

- косвенные риски - риски, которые по своей природе самостоятельно не оказывают достаточного влияния на деятельность банка, но могут повлечь к существенным потерям при взаимодействии со значимыми рисками;

- незначимые риски - риски, реализация которых не несет угрозы финансовому положению банка.

Для ранжирования рисков в рамках данных групп мы использовали два ключевых фактора: частота реализации данного риска и потенциальные потери (рис. 3). У каждого фактора равные веса и трехбалльная оценка. Суммарный балл, полученный их перемножением, распределяется по установленной экспертами банка шкале. В данном случае пунктирные линии условно разделяют оцениваемые риски на 3 группы по степени значимости слева направо, где от 1 до $2+-$ незначимые риски, от 2 - до $6+-$ косвенные и от 6 - до 9 - значимые риски. В данной системе мы условно разделили риски, имеющие балльную оценку 2 и 6 , на две группы. Категория $(+)$ включает в себя те риски, вероятность реализации (или потери от реализации) которых оценивается, например, в 2 балла, но имеют тенденцию к переходу в группу с низким риском. Если данной тенденции нет, то присваивается категория (-).

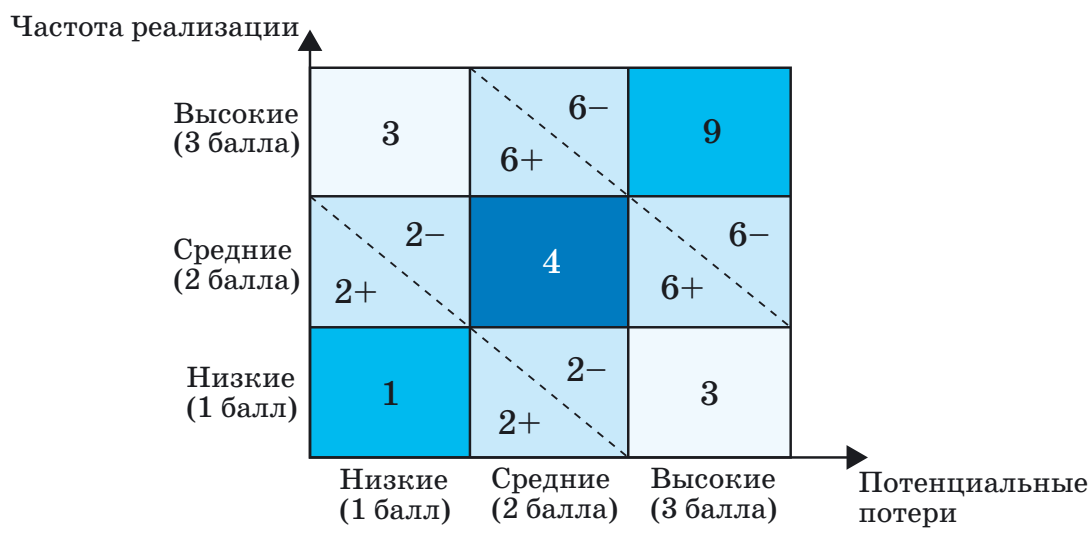

Рис. 3. Оценка значимости рисков кредитной организации

(Составлено по: [7])

\section{Baikal Research Journal}


Безусловно, банки могут самостоятельно устанавливать количество факторов и их влияние. Например, для данной модели мы можем дополнительно включить фактор скорости реализации риска и выстроить модель оценки с равными или неравными весами для каждого фактора.

На основе полученных данных о рисках мы можем рассчитать возможные потери, которые в целях соответствия методикам расчета Базельского комитета будем разделять на ожидаемые (Expected Losses $-E L$ ) и непредвиденные потери (Unexpected Losses - UL).

Ожидаемые потери представляют собой оценку средних прогнозируемых возможных потерь по отдельному активу, финансовому инструменту или операции (объекту риска), а также по их совокупности (далее портфелю). Как правило, ожидаемые потери должны покрываться доходами от данного портфеля и при этом определяют уровень резервов (бухгалтерских или управленческих), который должен быть сформирован под него.

Расчет ожидаемых потерь в рамках базового подхода может осуществляться через величину доначисления резервов на возможные потери по ссудам:

$$
E L=\Delta_{r} V_{p} \text {, }
$$

где $\Delta_{r}$ - ожидаемое досоздание резервов на горизонте в 1 год, $\% ; V_{p}$ - ожидаемый объем портфеля.

При этом ожидаемое досоздание резервов рассматривается как сумма двух величин: досоздание в связи с изменением качества портфеля или связанное с изменением его объема. Данный метод носит более регулятивный характер и является недостаточно гибким с точки зрения управления рисками и понимания особенностей работы банка.

По методике Базельского комитета, ожидаемые потери от реализации риска в общем виде рассчитываются как произведение трех переменных:

$$
E L=P D \cdot L G D \cdot E A D,
$$

где $P D$ - вероятность дефолта; $L G D$ - уровень потерь при дефолте; $E A D$ - стоимость под риском дефолта.

Вероятность дефолта $P D$ - риск неспособности заемщика выполнять свои обязательства при горизонте прогнозирования в один год. Данный показатель играет важную роль при оценке кредитного риска и должен быть рассчитан на основе исторического опыта и эмпирических данных (с учетом специфики кредита) [8].

Расчет рейтинга PD-модели основан на наборе характеристик клиента [9], разбиваемых на три основные группы:

- финансовые (выручка, уровень долга);

- нефинансовые (срок существования компании);

- поведенческие (использование предыдущих кредитных линий).

На наш взгляд, в данном случае применима градация, установленная положением «О порядке формирования кредитными организациями резервов на возможные потери по ссудам, по ссудной и приравненной к ней задолженности» от 26 марта 2004 г. № 254-П и внутренними методиками банка, где норма резервирования будет представлена как вероятность дефолта контрагента, а категории качества выступают своеобразными рейтинговыми группами. В рамках данного подхода необходимо учесть ряд факторов: финансовое положение заемщика, качество обслуживания долга (в том числе исторический опыт), состояние отрасли заемщика и срок существования компании.

Для отдельных контрагентов или инструментов, имеющих рейтинговую оценку, существует подход, применяемый рейтинговыми агентствами. Ими используются различные модели оценки вероятности дефолта для присвоения того или

\section{Baikal Research Journal}


иного класса для эмитента. Приведем далее оценку вероятности дефолта по модели $\mathrm{S} \& \mathrm{P}$ (табл. 1).

Таблица 1

Оценка вероятности дефолта по модели $S \& P, \%$

\begin{tabular}{|l|r|r|}
\hline \multicolumn{1}{|c|}{ Рейтинг S\&P } & Вероятность исполнения облигаций & $P D=1-$ гр. 2 \\
\hline AAA & 99,98 & 0,02 \\
\hline AA & 99,95 & 0,05 \\
\hline A & 99,87 & 0,13 \\
\hline BBB & 99,32 & 0,68 \\
\hline BB & 97,60 & 2,40 \\
\hline B & 88,36 & 11,64 \\
\hline
\end{tabular}

Источник: Unexpected Loss (UL), Expected Loss \& Economic Capital - A simple case study // finance training course URL : http://financetrainingcourse.com/education/2014/12/unexpected-loss-ul-expectedloss-economic-capital-case-study/.

Уровень потерь при дефолте $L G D$ - удельный вес потерь в случае дефолта контрагента. Является важным параметром в количественной оценке риска и определении необходимого капитала в рамках продвинутого подхода, основанного на внутренних рейтингах. Оценка данного параметра основывается на исторических данных о потерях с учетом анализа отдельных особенностей кредита в части наличия обеспечения, гарантий и степени их покрытия. Должна быть дана консервативная усредненная оценка на долгосрочную перспективу [8]. На наш взгляд, данный показатель стоит понимать следующим образом:

$$
L G D=1-\left(P_{\text {об }}-L_{p}\right) / E A D,
$$

где $P_{\text {об }}$ - рыночная стоимость обеспечения; $L_{p}-$ расходы от реализации обеспечения.

Показатель $L G D$ принимает значение от 0 до $100 \%$. Кроме того, в целях упрощения расчетов рекомендуется устанавливать фиксированное значение показателя $L_{p}$ для каждого типа обеспечения. Стоит также отметить, что в большинстве методик не учитываются расходы, связанные с реализацией обеспечения, однако, в целях более адекватного восприятия конкретного риска их целесообразно учесть (усредненно по типу обеспечения).

В мировой практике при работе с проблемной и просроченной задолженностью в этих целях применяется показатель $R R$ (RecoveryRate), который показывает долю возвращаемых средств в случае объявления заемщика дефолтом. Стоит также отметить, что наибольшее значение данный показатель принимает на ранних проблемных стадиях, когда банк может оказывать наибольшее влияние на ситуацию с заемщиком.

Стоимость под риском дефолта $E A D$ - объем задолженности заемщика в момент наступления дефолта. Рассчитывается как оставшийся объем задолженности под риском, спрогнозированный для кредита, по которому наступает дефолт при горизонте прогнозирования в один год. В отдельных случаях сюда могут включаться, например, невостребованные кредитные линии [8;9].

Вторым ключевым показателем в рамках данной методики является величина непредвиденных потерь (unexpected loses, или $U L$ ). Данный показатель представляют собой оценку максимально возможного превышения потенциальных или реализованных потерь над ожидаемыми потерями, которая может быть превзойдена только в задаваемом ограниченном числе случаев при реализации неблагоприятных событий [9].

Величина показателя $U L$ будет определяться в данном случае исходя из расчета разницы между потерями банка, которые он в течение года не превысит с вероятностью 99,8 \% , и ожидаемыми потерями (рис. 4).

\section{Baikal Research Journal}

электронный научный журнал Байкальского государственного университета 


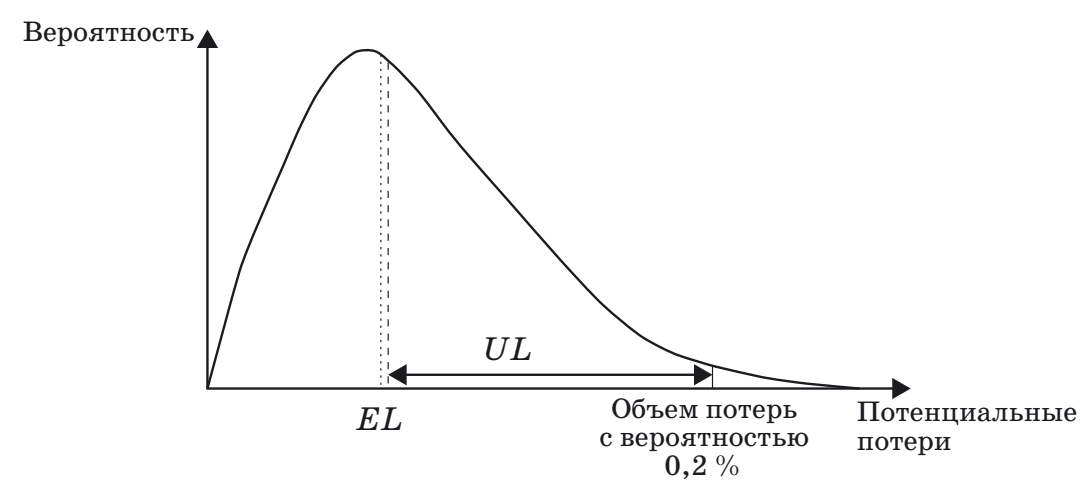

Рис. 4. Ожидаелье и непредвиденные потери кредитной организации (Источник: [10])

График демонстрирует примерную функцию распределения с отмеченными значениями $E L$ и $U L$. Площадь под кривой до определенного уровня характеризует вероятность того, что потери в течение года не превысят этого значения [10]. На наш взгляд, в рамках однофакторной модели данные потери можно представить как разницу между наихудшим (стрессовым) и базовым сценариями.

Определение величины непредвиденных потерь сводится к трем методам:

1. Базовый регулятивный метод, определяемый в документах Базельского комитета как стандартизованный подход для банков, не имеющих продвинутых методик оценки $U L$.

В соответствии с этим методом:

$$
U L=R W A \cdot H_{\min }
$$

где $R W A$ - (Risk-weighted asset) общая сумма взвешенных с учетом кредитного риска активов по методике, определенной Банком России, в частности инструкцией 139-И; $H_{\min }$ - минимальное значение соответствующего норматива достаточности капитала, \% .

С 1 января 2016 г. минимальное значение $\mathrm{H} 1.0$ составляет 8 \% , также регулятором устанавливаются следующие надбавки:

- антициклическая надбавка;

- надбавка на поддержание достаточности капитала;

- надбавка за системную значимость.

Все надбавки определяются расчетным путем согласно инструкции 139-И. Кроме того, их минимальное значение с каждым годом увеличивается (начиная с 2016 г. и до 2019 г.). Так, для не системно-значимых банков минимальное значение норматива достаточности Н1.0 с 1 января 2016 г. с учетом надбавки на поддержание достаточности капитала составит 8,625 \% (предполагается, что банк размещает активы в странах, где величина антициклической надбавки составляет $0 \%$, например, в России).

Базовый метод оценки $U L$ не отражает:

- качества внутренней системы риск-менеджмента;

- собственных оценок риска кредитного портфеля;

- наличия обеспечения;

- дисциплины возврата долга.

2. Статистические методы, в соответствии с которыми непредвиденные потери определяются через квантили распределения потерь по кредитному или рыночному портфелю по $V a R$ (Value-at-Risk) методологии с заданным уровнем надежности за вычетом величины ожидаемых потерь.

\section{Baikal Research Journal}


В соответствии со статистическими методами непредвиденные потери определяются как разность между квантилем распределения потерь, вычисляемом на кредитном портфеле на основе статистических или модельных методов, и ожидаемыми потерями. Например, если Банк внедрил у себя модель внутреннего кредитного рейтинга, то основным методом оценки является математическое моделирование параметров риска, рассматривающее $P D, L G D$ и $E A D$ как случайные величины с той или иной степенью коррелируемости [9].

3. Метод сценарного моделирования оценки $U L$ (например, на пулах кредитов портфеля с максимальным уровнем потерь). По сути, данный метод представляет собой несколько примерно одинаково вероятных, но значимо контрастных вариантов будущего развития внешней среды с акцентом на тех позициях, которые являются значимыми для менеджеров организации при принятии стратегических решений.

Выбор того или иного подхода в рамках расчета неожидаемых потерь осуществляется банком самостоятельно. Предпочтительными являются те методы, которые позволяют дать оценку собственного видения уровня неожидаемых потерь (например, статистический). Любые методы, которые в своем подходе используют те или иные базовые методики с использованием, например, $R W A$, не дают максимального эффекта оценки рисков.

Таким образом, ожидаемые потери являются неизбежными и регулярными и для их покрытия необходимы резервы по ожидаемым потерям, а неожидаемые потери являются значительными по своей сути и связаны в основном с проявлением кризисных ситуаций. Для их покрытия необходим экономический капитал. Оценка ожидаемых и непредвиденных затрат в дальнейшем поможет определить рентабельность экономического капитала.

Экономический капитал представляет собой наибольшую величину возможных потерь на заданном горизонте времени, рассчитанную с определенным доверительным интервалом и в соответствии с внутренними методиками банка. Основные отличительные черты регуляторного и экономического капиталов указаны в табл. 2.

Таблица 2

Отличительные черты регуляторного и эконолического капиталов

\begin{tabular}{|c|c|c|}
\hline Признак & Экономический капитал & Регуляторный капитал \\
\hline Показатели & $\begin{array}{l}\text { Отношение взвешенных с учетом уровня риска активов } \\
\text { к экономическому капиталу, рентабельность экономи- } \\
\text { ческого капитала, экономическая прибыль }\end{array}$ & $\begin{array}{l}\mathrm{H} 1.0, \mathrm{H} .1 .1, \mathrm{H} 1.2, \\
\mathrm{H} 20.0, \mathrm{H} 20.1, \mathrm{H} 20.2\end{array}$ \\
\hline $\begin{array}{l}\text { Основной } \\
\text { пользователь }\end{array}$ & $\begin{array}{l}\text { Руководство банка, акционеры, Банк России (в рамках } \\
\text { внутренних процедур оценки достаточности капитала) }\end{array}$ & ЦБ РФ ${ }^{1}$ \\
\hline $\begin{array}{l}\text { Методология } \\
\text { расчета }\end{array}$ & Внутренняя методика & 139-И, 385-П, 139-И+² \\
\hline $\begin{array}{l}\text { Стандарт } \\
\text { отчетности }\end{array}$ & Любой стандарт отчетности & РСБУ \\
\hline $\begin{array}{l}\text { Информатив- } \\
\text { ность }\end{array}$ & $\begin{array}{l}\text { Дает объективную оценку деятельности и повышает } \\
\text { качество принимаемых управленческих решений, так } \\
\text { как более чувствительный к рискам и учитывает спе- } \\
\text { цифику деятельности банка }\end{array}$ & $\begin{array}{l}\text { Дает информацию о со- } \\
\text { ответствии деятельно- } \\
\text { сти банка требованиям } \\
\text { регулятора }\end{array}$ \\
\hline
\end{tabular}

${ }^{1}$ В случае отсутствия возможности расчета иных показателей, отличных от установленных Банком России, могут быть взяты за основу руководством банка и акционерами в качестве ключевых показателей.

${ }^{2}$ B 139-И+ добавляются прочие риски и ALM, оцениваемые по внутренней методологии.

Расчет экономического капитала представляет собой:

$$
E C A P=U L\left(1+E_{c a p}\right),
$$

где $U L-$ неожидаемые потери на единицу кредитного продукта, $\% ; E_{c a p}-$ подушка капитала, характеризующая требуемую степень покрытия капиталом номинала кредитного продукта.

\section{Baikal Research Journal}


Для эффективного управления капиталом важно создать такую систему, которая позволит контролировать как экономический, так и регуляторный капиталы. Для этого необходимо:

Разработать единую систему лимитов на базе соответствующих показателей. Для регуляторного капитала установить лимиты на базе показателей достаточности Банка России, а для экономического капитала - целевое значение RAROC ${ }^{2}$, в том числе отдельно по бизнес-подразделениям.

Определить ограничения по регуляторному капиталу на таком уровне, который позволит соблюдать все необходимые нормативы достаточности капитала как на уровне банка, так и на уровне банковской группы, в том числе проанализировать плановую структуру капитала и выявить наиболее жесткое регуляторное ограничение для каждого его уровня.

На горизонте планирования в год определить: риск-аппетит по каждому капиталу и факторы, влияющие на пропорции изменений их величины, т. е. как изменение при заданном сценарии одного капитала повлияет на отдачу и изменение другого (например, при установленных разных весах на конкретный тип актива).

Разработать мероприятия по увеличению отдачи на капитал (регуляторный/ экономический) путем изменения лимитов и (или) установления ограничений на конкретный вид операций, передислокации ресурсов из одного бизнес-подразделения в другое, изменения структуры портфеля и т. д.

В целях регулирования экономического капитала оптимальным показателем, на наш взгляд, является RAROC [11], рассчитываемый следующим образом:

$$
R A R O C=\frac{\text { Чистал прибыль }+(\text { Резервы-EL }+ \text { Capital Benefit })(1-\text { Ставка налога })}{\text { Эконолический капитал }},
$$

где Capital Benefit - выгода, возникающая у банка от наличия капитала, так как банк не платит проценты за его использование.

На основе принципа $R A R O C$ разработаны интегрированные подходы к измерению риска, которые дают возможность вычислить необходимый капитал для покрытия всех рисков компании; понять, куда вкладываются средства акционеров; сравнить доходы с учетом рисков по различным направлениям бизнеса; определить возможности для перемещения риска $[12 ; 13]$.

Предположим, что кредитная организация развивает три направления бизнеca: розничное, корпоративное и на финансовых рынках. В рамках распределения капитала важно понимать, какое из направлений имеет наилучшее соотношения риска и доходности, т. е. максимальное значение $R A R O C$. После оценки рентабельности капитала по каждому сегменту наилучший результат был зафиксирован у блока по работе на финансовых рынках (рис. 5). При этом корпоративный блок приносит наибольший доход. Однако в текущих условиях корпоративное кредитование связано с проявлением дополнительных рисков и частым досозданием резервов, что делает данное направление потенциально нерентабельным для банка. В данном случае наибольшую отдачу приносит блок по работе на финансовых рынках, т. е. в условиях текущего состава активов. В целях выполнения показателя доходности по банку в целом целесообразно перераспределить часть экономического капитала из корпоративного блока в блок по работе на финансовых рынках при условии, что последний сможет выдержать дополнительный объем при том же уровне риска и доходности.

${ }^{2}$ RAROC (Risk-adjusted return on capital) - показатель, характеризующий рентабельность капитала, скорректированную на риск.

\section{Baikal Research Journal}

электронный научный журнал Байкальского государственного университета 


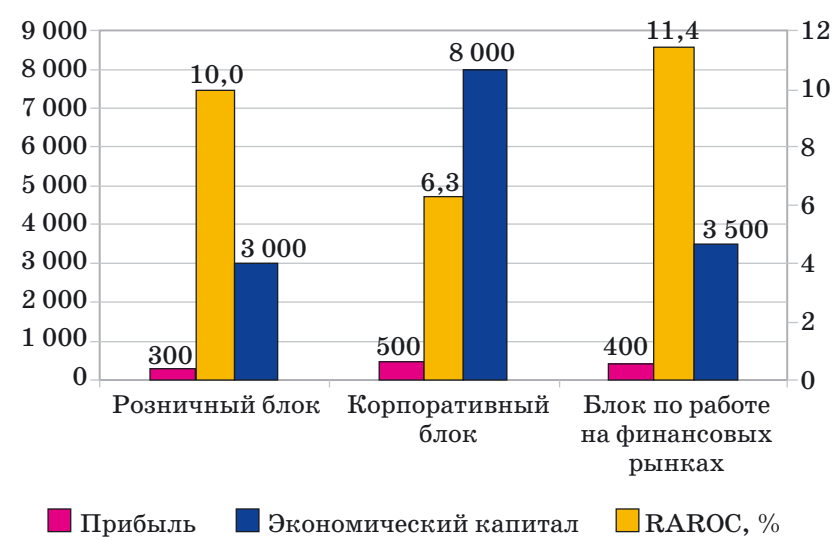

Рис. 5. Финансовые показатели деятельности сеглентов бизнеса банка

При этом необходимо учитывать потребление регуляторного капитала при принятии решений на всех уровнях, так как он является основным ограничивающим фактором [11], а именно:

- принятие решений по условиям заключения сделок, установлении лимитов на контрагентов;

- установление лимитов капитала на бизнес-направления.

Однако регуляторный капитал не чувствителен к риску в достаточной степени, и использование регуляторного капитала без одновременной оптимизации отдачи на экономический капитал может привести к формированию непривлекательных с точки зрения отдачи с учетом риска пула активов. Таким образом, предлагаем для принятия управленческих решений использовать комбинированный показатель [11], позволяющий одновременно оптимизировать RAROC, экономическую прибыль и регуляторный капитал:

$$
E P R C=\frac{\text { Эконолический капитал }}{\text { Регулярный капитал }}=\frac{(\text { RAROC }- \text { HR) Эконолический капитал }}{\text { Регулярный капитал }},
$$

где $E P R C$ - экономическая цена регуляторного капитала; $H R$ - требуемая акционерами доходность.

Методики, основанные на принципах $R A R O C$, представляют собой интегрированный подход, связывающий риск, капитал и стоимость и сфокусированный на сравнении использования капитала и доходности в свете различных направлений бизнеса и типов риска. Они оценивают все риски, которые на себя берет банк, и измеряют экономический капитал на базе каждого взятого в отдельности риска, а также их корреляцию.

Подводя итог, стоит сказать, что на сегодняшний день в условиях экономического кризиса и неопределенности внешней среды для банков важно принимать әффективные управленческие решения, устанавливать оптимальный уровень риск-аппетита и выработать такую систему распределения капитала, которая позволит получить наибольшую отдачу от его использования. В целях этого необходимо применять такие подходы, которые позволят правильно оценить доходность активов банка и учитывать специфику его работы. Расчет рентабельности капитала с учетом уровня принимаемого риска и внедрение продвинутых подходов в их оценке позволят значительно повысить культуру управления рисками в банковском секторе и эффективность распределения капитала банков.

\section{Baikal Research Journal}




\section{Список использованной литературы}

1. Брыткова А. «Число зверя» : сколько банков нужно России? [Электронный ресурс]. Режим доступа : http://www.banki.ru/news/daytheme/?id=8008688.

2. Спиридонова Л. В. Риск-стратегия как инструмент управления организацией в условиях неопределенности : дис. ... канд. экон. наук : 08.00.05 : 08.00.10 / Л. В. Спиридонова. Сургут, 2011. - 138 с.

3. Волков И. М. Проектный анализ: продвинутый курс : учеб. пособие / И. М. Волков, М. В. Грачев. - М. : Инфра-М, 2004. - 495 с.

4. Воронов Г. А. Процессный подход в управлении организациями в условиях неопределенности [Электронный ресурс] / Г. А. Воронов, А. Р. Грошев // Современные проблемы науки и образования. - 2012. - № 3. - Режим доступа : http://www.science-education.ru/ $\mathrm{ru} /$ article/view?id=6294.

5. Мирошниченко О. С. Собственный капитал банка: проблемы регулирования / О. С. Мирошниченко. - М. : Весь мир, 2012. - 244 с.

6. Емельченков В. А. Агрегирование рисков в рамках ВПОДК [Электронный ресурс]/ В. А. Емельченков. - Режим доступа : http://arb.ru/b2b/conf.

7. Кузнеченко О. Подходы к идентификации рисков в рамках ВПОДК [Электронный ресурс] / О. Кузнеченко // Профессиональный банковский форум «Регулирование банковских рисков - 2016». - Режим доступа : http://arb.ru/b2b/conf.

8. Farid J. A. Internal Capital Adequacy Assessment Process (ICAAP) - Overview and Core Concepts [Electronic resource] / J. A. Farid, F. Salahuddin. - Mode of access : https://books. google.ru/books?id=uc7aTNJKOwIC\&printsec=frontcover\&hl=ru\&source=gbs_ge_summary_ $\mathrm{r} \& \mathrm{cad}=0 \# \mathrm{v}=$ onepage $\& \mathrm{q} \& \mathrm{f}=$ false.

9. Бухтин М. А. Внутренние процедуры управления достаточностью капитала в банке в соответствие с указанием Банка России N 3624-У от 15.04.2015 [Электронный ресурс] / М. А. Бухтин. - Режим доступа : http://arb.ru/b2b/conf.

10. Бруссер П. А. Показатель RAROC и методика его расчета [Электронный ресурс] / П. А. Бруссер. - Режим доступа : http://mgimo.ru/files/238488/presentation_15.pdf.

11. Архипова Е. Увеличение отдачи на капитал при условии соблюдения регуляторных нормативов [Электронный ресурс] / Е. Архипова. - Режим доступа : http://arb.ru/ $\mathrm{b} 2 \mathrm{~b} /$ conf.

12. Еремчева Ю. С. Ценообразование кредитных продуктов банка с учетом риска / Ю. С. Еремчева, С. В. Долженко // Управление финансовыми рисками. — 2009. — № 2. C. $18-22$.

13. Pfetsch S. Mastering ICAAP / S. Pfetsch, T. Poppensieker, S. Schneider, D. Serova // McKinsey Working Papers on Risk. — 2011. - № 27. - P. 1-22.

\section{References}

1. Brytkova A. «Chislo zverya»: skol'ko bankov nuzhno Rossii? [ «Number of the Beast»: how many banks does Russia need?]. Available at: http://www.banki.ru/news/daytheme/?id=8008688. (In Russian).

2. Spiridonova L. V. Risk-strategiya kak instrument upravleniya organizatsiei $v$ usloviyakh neopredelennosti. Kand. Diss. [Risk strategy as an instrument of corporate management in uncertain environment. Cand. Diss.]. Surgut, 2011. 138 p.

3. Volkov I. M., Grachev M. V. Proektnyi analiz: prodvinutyi kurs [Project analysis: an advanced course]. Moscow, Infra-M Publ., 2004. $495 \mathrm{p}$.

4. Voronov G. A., Groshev A. R. Process approach in management of organizations in uncertain environment. Sovremennye problemy nauki $i$ obrazovaniya $=$ Recent developments in science and education, 2012, no. 3. Available at: http://www.science-education.ru/ru/article/ view?id=6294. (In Russian).

5. Miroshnichenko O. S. Sobstvennyi kapital banka: problemy regulirovaniya [Bank stock: problems of regulation]. Moscow, Ves' mir Publ., 2012. 244 p.

6. Emel'chenkov V. A. Agregirovanie riskov $v$ ramkakh VPODK [Aggregating risks in the frame of VPODK. Available at: http://arb.ru/b2b/conf. (In Russian).

7. Kuznechenko O. Podkhody $k$ identifikatsii riskov $v$ ramkakh VPODK [Approaches to identifying risks in the frame of VPODK]. Available at: http://arb.ru/b2b/conf. (In Russian).

\section{Baikal Research Journal}


8. Farid J. A., Salahuddin F. Internal Capital Adequacy Assessment Process (ICAAP) Overview and Core Concepts. Available at: https://books.google.ru/books?id=uc7aTNJKO-

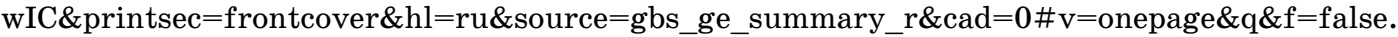

9. Bukhtin M. A. Vnutrennie protsedury upravleniya dostatochnost'yu kapitala $v$ banke $v$ sootvetstvie s ukazaniem Banka Rossii № 3624-U ot 15.04.2015 [Internal procedures of managing bank capital adequacy in accordance with the instruction of Bank of Russia № 3624-У of 15.04.2015]. Available at: http://arb.ru/b2b/conf. (In Russian).

10. Brusser P. A. Pokazatel' RAROC i metodika ego rascheta [RAROC indicator and method of its calculation]. Available at: http://mgimo.ru/files/238488/presentation_15.pdf. (In Russian).

11. Arkhipova E. Uvelichenie otdachi na kapital pri uslovii soblyudenīya regulyatornykh normativov [Increasing return on equity in terms of regulatory compliance]. Available at: http:// arb.ru/b2b/conf. (In Russian).

12. Eremcheva Yu. S., Dolzhenko S. Pricing of bank credit products in terms of risks. Upravlenie finansovymi riskami = Management of financial risks, 2009, no. 2, pp. 18-22. (In Russian).

13. Pfetsch S., Poppensieker T., Schneider S., Serova D. Mastering ICAAP. McKinsey Working Papers on Risk, 2011, no. 27, pp. 1-22.

\section{Информация об авторах}

Грошев Александр Роланович - доктор экономических наук, профессор, кафедра финансов, денежного обращения и кредита, Сургутский государственный университет, 628412 , г. Сургут, ул. Ленина, 1, e-mail: arg.sochi@yandex.ru.

Павлов Вячеслав Сергеевич - аспирант, кафедра финансов, денежного обращения и кредита, Сургутский государственный университет, 628412, г. Сургут, ул. Ленина, 1, e-mail: pavlov.sl@icloud.com.

\section{Authors}

Aleksandr R. Groshev - Doctor habil. (Economics), Professor, Chair of Finance, Money Circulation and Credit, Surgut State University, 1 Lenin St., 628412, Surgut, Russian Federation; e-mail: arg.sochi@yandex.ru.

Vyacheslav S. Pavlov - PhD Student, Chair of Finance, Money Circulation and Credit, Surgut State University, 1 Lenin St., 628412, Surgut, Russian Federation; e-mail: pavlov.sl@icloud.com.

\section{Библиографическое описание статьи}

Грошев А. Р. Оценка эффективности использования капитала банка с учетом принимаемых рисков / А. Р. Грошев, В. С. Павлов // Baikal Research Journal. — 2016. — T. 7, № 4. DOI : $\underline{10.17150 / 2411-6262.2016 .7(4) .8}$.

\section{Reference to article}

Groshev A. R., Pavlov V. S. Assessing efficiency of using bank equity in terms of accepted risks. Baikal Research Journal, 2016, vol. 7, no. 4. DOI : 10.17150/2411-6262.2016.7(4).8. (In Russian).

\section{Baikal Research Journal}

